\title{
La vocación de Josemaría Escrivá de Balaguer (1918-1928)
}

\section{The Vocation of Josemaría Escrivá de Balaguer (1918-1928)}

\section{José Luis GonZÁLEZ GULLÓN}

Istituto Storico Josemaría Escrivá Pontificia Università della Santa Croce Roma. Italia ID ORCID 0000-0002-9901-7720 jggullon@gmail.com

Resumen: La vida de las personas declaradas como santos por la Iglesia está marcada por eventos en los que se sintieron llamados interiormente por la gracia divina. En el caso de los fundadores, estos sucesos tienen una componente carismática que marca la evolución de las instituciones que inician. La biografía de san Josemaría Escrivá de Balaguer se mueve en estas coordenadas. Un suceso singular del que se conmemora el centenario -las huellas que dejaban unos carmelitas descalzos en la nieve- le llevaron al descubrimiento de su vocación en la Iglesia y a una profundización personal en el misterio cristiano. Este artículo analiza el contenido de lo que el propio Escrivá de Balaguer denominó más tarde «barruntos», es decir, presentimientos de que Dios le quería para una determinada misión.

Palabras clave: Sacerdocio, San Josemaría Escrivá de Balaguer, Vocación sacerdotal.
Abstract: The life of a man or woman declared as saint by the Church is marked by events in which he or she had the internal feeling of a divine call. In the case of the founders, those episodes have a charismatic nature related with the institution they founded. The biography of St. Josemaría Escrivá de Balaguer develops in the same way. A particular incident -the footprints in the snow of some barefooted Carmelites- led him to the discovery of his vocation in the Church and to understand better the Christian mysteries. This article analyzes the content of what Escrivá de Balaguer later calls «premonitions», that is, the feeling that God destined him for a particular mission.

Keywords: Priesthood, Saint Josemaría Escrivá, Priestly Vocation. 
$\ll T$

oda la vida es vocación» ${ }^{1}$. Del principio al final de la existencia, Dios llama a cada hombre a través de etapas y circunstancias en las que, a veces, se siente la vocación de modo impetuoso y otras de forma casi imperceptible. Dentro del amplio y rico panorama teológico y jurídico al que hace referencia la vocación cristiana, nuestro estudio -de marcado carácter histórico- analiza el momento en el que José María Escrivá sintió que Dios pasaba por su vida y la evolución de ese suceso hasta que recibió la misión de fundar el Opus Dei². Estudiaremos una década que comenzó a finales de 1917 o principios de 1918 -lo que denominó una vez el momento «de mi vocación en Logroño» ${ }^{3}-$ y que concluyó en octubre de 1928 con la fundación del Opus Dei. Estos diez años coinciden con su adolescencia y juventud, una fase de la vida en la que cada persona aprende a amar con libertad y forja grandes ideales ${ }^{4}$.

Hemos dividido el artículo en cinco apartados. Comienza con una breve referencia a la infancia y adolescencia de José María Escrivá. Después, analizamos los sucesos del momento en el que comienza su vocación; a continuación, nos referiremos a los años de seminario en Logroño y Zaragoza; luego, examinamos cuál era su estado interior durante esa época; y, finalmente, mencionamos el suceso fundacional del Opus Dei, que da fin a esta etapa de su vida.

\section{ADVERSIDADES DE UNA FAMILIA CRISTIANA}

José María Escrivá Albás nació en Barbastro, Huesca, el 9 de enero de 1902. Su padre se llamaba José Escrivá Corzán; había nacido en Fonz (Huesca), en 1867, aunque su familia procedía de Balaguer (Lérida). Su madre se llamaba Dolores Albás Blanc. Era barbastrina, con antepasados en Aínsa (Hues-

${ }^{1}$ OCÁRIZ, F., «La vocación al Opus Dei como vocación en la Iglesia», en RodríguEz P., OCÁRIZ, F. e Illanes, J. L., El Opus Dei en la Iglesia, 6a ed., Madrid: Rialp, 2014, 142. Las cursivas son del original.

2 En nuestro artículo aparecerá el nombre del fundador del Opus Dei como se utilizaba en los años treinta del siglo pasado, es decir, José María Escrivá Albás: GonZÁlez Gullón, J. L., DYA. La Academia y Residencia en la historia del Opus Dei (1933-1939), Madrid: Rialp, 2016, 11, nt. 1.

3 Apuntes íntimos, n. 289 (17-IX-1931), en VÁZQueZ DE PraDA, A., El Fundador del Opus Dei, vol. I («iSeñor, que vea!»), Rialp, Madrid 1997, 100. Sobre el contenido y alcance de esta fuente, puede verse Escrivá de Balaguer, J., Camino. Edición crítico-histórica preparada por Pedro Rodríguez, $3^{a}$ ed., Madrid: Rialp, 2004, 18-27; y RodrígueZ, P., «Apuntes íntimos (obra inédita)», en ILLANES, J. L. (coord.), Diccionario de san Fosemaría Escrivá de Balaguer, Burgos: Monte Carmelo e Instituto Histórico San Josemaría Escrivá, 2013, 131-135.

${ }^{4}$ Desde el punto de vista de la biografía de Escrivá, estos años pueden verse en VázQUEZ DE PRADA, A., El Fundador del Opus Dei, cit., 13-250. 
ca). La pareja se había casado cuatro años antes, en 1898, y residían en una casa alquilada en la calle Mayor de Barbastro, que hacía ángulo a la Plaza del Mercado. En 1899, había nacido la primogénita, Carmen ${ }^{5}$.

La población barbastrina no sobrepasaba los siete mil habitantes. A pesar de su escaso número, acogía una sede episcopal desde hacía ocho siglos. La economía de la ciudad giraba en torno a diversas actividades agrícolas, como el cereal o la producción de vino y aceite. Los comerciantes y pequeños empresarios convivían con los campesinos y jornaleros. Había tendencias políticas de diverso tipo, desde las carlistas -legitimistas y partidarios del Antiguo Régimen- hasta las republicanas y socialistas. En los círculos recreativos y culturales dominaba el pensamiento liberal, sin que hubiese graves conflictos políticos o sociales.

A finales del siglo XIX, José Escrivá y otros dos socios crearon una empresa dedicada al comercio de tejidos y la venta de chocolate. En 1902, un socio se retiró con el compromiso de no poner un negocio del mismo tipo en Barbastro. José Escrivá estableció junto al otro socio una nueva sociedad llamada «Juncosa y Escrivá». En un primer momento, esta actividad empresarial dio buenos resultados. La familia Escrivá disfrutó de una posición relativamente acomodada. De acuerdo con los usos de la época, tenía cuatro personas de servicio en la casa. José Escrivá poseía un alto sentido de la solidaridad, manifestado en las limosnas que entregaba a personas menesterosas, la colaboración económica con el Centro Católico de la ciudad, y la organización de conferencias religiosas para sus empleados ${ }^{6}$.

A los cuatro días de su nacimiento, José María fue bautizado en la catedral de Barbastro que, además, era su parroquia. Poco después -el 23 de abrilrecibió la confirmación. En 1904, cuando tenía dos años, sufrió una meningitis aguda. Desahuciado por los médicos, su madre rezó una novena a Nuestra Señora del Sagrado Corazón y le prometió que, si el niño curaba, iría a visitarla en peregrinación a una ermita dedicada a Nuestra Señora de Torreciudad, a veinte kilómetros de Barbastro. El pequeño sanó y su madre lo llevó en brazos hasta Torreciudad como agradecimiento.

\footnotetext{
5 Sobre este periodo, ver PIOpPI, C., «Infanzia e prima adolescenza di Josemaría Escrivá: Barbastro 1902-1915. Contesti, eventi biografici, stato delle ricerche e prospettive di approfondimento», Studia et Documenta 8 (2014) 149-189; Mora-FigueroA, J., «Barbastro», en IllanES, J. L. (coord.), Diccionario de san fosemaría Escrivá de Balaguer, cit., 153-157; y Toranzo, E., ToranZO, G. y Toranzo, E. L., Una familia del Somontano, Madrid: Rialp, 2004.

${ }^{6}$ Vázquez de Prada, A., El Fundador del Opus Dei, cit., 49.
} 
La familia Escrivá estaba muy unida. José María aprendió de sus padres virtudes como la libertad unida a la responsabilidad, la laboriosidad y el orden. También le enseñaron a rezar con una piedad sencilla, sin artificio. Según recordaba más tarde, «nuestro Señor fue preparando las cosas para que mi vida fuera normal y corriente, sin nada llamativo. Me hizo nacer en un hogar cristiano, como suelen ser los de mi país, de padres ejemplares que vivían y practicaban su fe» ${ }^{7}$.

En los años siguientes llegaron tres niñas al hogar: María Asunción, Chon, en 1905; María de los Dolores, Lolita, en 1907; y María del Rosario, en 1909. Tristemente, la mortandad infantil se llevó a una detrás de otra. Rosario falleció con nueve meses, Lolita con cinco años, y Chon con ocho.

A pesar de estas duras contrariedades, la mayor parte de la infancia de José María fue normal, alegre, de progresiva apertura a la sociedad y al mundo. Entre 1905 y 1908 asistió a un parvulario regentado por las Hijas de la Caridad; y de 1908 a 1915 fue alumno de un colegio de los padres escolapios. En 1912 -año en que comenzaba la educación secundaria- recibió la Primera Comunión en la escuela, beneficiándose de la disposición del papa Pío X para que se comulgara al llegar al uso de razón. Cuando recibió a Jesús sacramentado, José María le pidió la gracia de no cometer nunca un pecado grave ${ }^{8}$.

Debido a la coyuntura económica del momento y a que el antiguo socio no había cumplido el compromiso de no hacer competencia, la sociedad «Juncosa y Escrivá» entró en crisis. Juan Juncosa y José Escrivá demandaron a aquel socio. El Juzgado de primera instancia de Barbastro falló a favor de la empresa en 1910. Como consecuencia de una apelación, la Sala de lo civil de la Audiencia Territorial de Zaragoza también dio una sentencia favorable a «Juncosa y Escrivá» en 1912, aunque rebajó la indemnización a que tenía derecho. La sociedad, que estaba entonces en fase de liquidación por haber terminado su periodo social, presentó un recurso de casación. En mayo de 1913, el Tribunal Supremo rechazó el recurso y obligó a pagar los costes del pleito. «Juncosa y Escrivá» quebró y cedió el activo social a una comisión de acreedores. En 1915, otra sentencia del Tribunal Supremo falló a favor de un pleito presentado por algunos acreedores. El negocio quedaba definitivamente cancelado?.

${ }^{7}$ Citado en Garrido, M., Barbastro y el Beato Fosemaría Escrivá, Barbastro: Ayuntamiento de Barbastro, 1995, 36.

${ }^{8}$ IbarRa Benlloch, M., «Josemaría Escrivá de Balaguer y el colegio de las Escuelas Pías de Barbastro (1908-1915)», Studia et Documenta 7 (2013) 201-220; y VÁZQUEZ DE PRADA, A., El Fundador del Opus Dei, cit., 51.

9 Toranzo, E., Toranzo, G. y Toranzo, E. L., Una familia del Somontano, cit., 85-87. 
Como el patrimonio social de la empresa resultaba insuficiente para resarcir las deudas, José Escrivá pagó a los acreedores con su capital familiar. No estaba obligado legalmente pero pensaba en conciencia que debía hacerlo. Esta resolución fue respaldada por su mujer; en cambio, no fue entendida por otros parientes políticos. La familia Escrivá Albás quedó en la ruina. Tuvo que prescindir de las personas que trabajaban en el servicio de la casa y comenzó a pasar estrecheces. José María sufrió una crisis interior porque esas dificultades económicas se unían al dolor por la muerte de sus hermanas. Pero la serena resignación cristiana de sus padres ante las adversidades le ayudaron a mantener la confianza en Dios.

En marzo de 1915, José Escrivá encontró trabajo como dependiente en $\mathrm{La}$ Gran Ciudad de Londres, una tienda de tejidos de la ciudad de Logroño. Después del verano de ese año, trasladó toda la familia a la capital riojana, que por entonces tenía veinticuatro mil habitantes. Los Escrivá Albás afrontaron las incomodidades propias del cambio de localidad y de la inicial ausencia de amistades.

Carmen se matriculó en Magisterio, carrera que acabaría en 1921. José María siguió los estudios de bachillerato en el Instituto General y Técnico, que pasó más tarde a llamarse Instituto Práxedes Mateo Sagasta. Por las mañanas acudía al instituto y por las tardes iba al colegio de San Antonio de Padua donde estudiaba y recibía clases complementarias, como era habitual en esa época ${ }^{10}$.

\section{EL DESCUBRIMIENTO DE LA LLAMADA}

En diciembre de 1917, José María Escrivá realizaba el último curso de bachillerato en Logroño. Por entonces, pasaba un periodo de cierta confusión. Además de las dudas propias de la adolescencia, mantenía una rebeldía interior ante la situación en la que se encontraba la familia -estaban abiertas las heridas de la muerte de sus hermanas y de la ruina de su padre, José Escriváy porque había cambiado de colegios y de amistades. Como recordaba años más tarde, «me rebelaba ante la situación de entonces. Me sentía humillado» ${ }^{11}$. En cambio, le impresionaba la serenidad y gran confianza en la Providencia que encontraba en sus padres, pues les veía sufrir en silencio.

10 Toldrá, J., «Instituto General y Técnico de Logroño», en Illanes, J. L. (coord.), Diccionario de san Fosemaría Escrivá de Balaguer, cit., 643-644.

11 Meditación, 14-II-1964, en EsCRIVÁ DE BALAGUER, J., En diálogo con el Señor, edición críticohistórica preparada por Luis Cano y Francesc Castells, Madrid: Rialp, 2017, 199. 
Entre el 9 de diciembre de 1917 y el 6 de enero de 1918 hubo doce días en los que nevó, con intensidad variable, en Logroño. El punto álgido se produjo a finales de diciembre, con fuertes nevadas y con una mínima de dieciséis grados bajo cero registrada el día 30 de diciembre. Al menos una persona anciana falleció en su casa a causa del frío ${ }^{12}$.

Uno de esos días, después de una nevada, José María Escrivá se encontraba en la calle Mayor. Tal vez iba o regresaba a su casa, situada en la calle Sagasta n. 12, muy cerca del Puente de Hierro, o quizá había ido al colegio de San Antonio de Padua. Cuando estaba a la altura del colegio de los hermanos maristas, en una zona llamada la Costanilla, vio de repente a «unos religiosos Carmelitas, descalzos sobre la nieve» ${ }^{13} \mathrm{y}$, como reacción, se planteó una pregunta en primera persona: «Si otros hacen tantos sacrificios por Dios y por el prójimo, ¿no voy a ser yo capaz de ofrecerle algo?» ${ }^{14}$. Entonces, le vino el pensamiento de ser sacerdote, algo que hasta ese momento no había considerado que fuese para él ${ }^{15}$.

\section{El SACERDOCIO SECULAR}

Enseguida -quizá unos días después de cumplir dieciséis años el 9 de enero de 1918- el joven José María acudió al convento donde vivían los carmelitas, que estaba situado a las afueras de la ciudad, en un camino carretero que se llamaba la Vuelta del Peine, al otro lado de las vías del ferrocarril. Pocas semanas

12 Toldrà Parés, J., Fosemaría Escrivá en Logroño (1915-1925), Madrid: Rialp, 2007, 121-122.

13 Apuntes íntimos, n. 1637b (4-X-1932), en VÁZqUEZ DE PradA, A., El fundador del Opus Dei, cit., 80, nt. 98. Éste es el recuerdo más antiguo de Escrivá sobre el episodio de los carmelitas caminando sobre la nieve. Puede ser que esos religiosos fuesen con los pies desnudos, pero lo más probable -era lo habitual-, es que llevasen unas sandalias ligeras y abiertas. La Costanilla está situada a la altura del actual número 107 de la calle Marqués de san Nicolás.

${ }^{14}$ Frase escuchada al fundador por Álvaro del Portillo y recogida en VÁzQUEZ de Prada, A., El fundador del Opus Dei, cit., 96.

15 Catorce años después de estos sucesos, en 1932, Escrivá realizó unos ejercicios espirituales en el convento del Carmen de Segovia. Un día apuntó: «Mi Madre del Carmen me empujó al sacerdocio. Yo, Señora, hasta cumplidos los dieciséis años, me hubiera reído de quien dijera que iba a vestir sotana. Fue de repente, a la vista de unos religiosos Carmelitas, descalzos sobre la nieve...», Apuntes intimos, n. 1637b (4-X-1932; las cursivas son nuestras), en VÁZqueZ DE PradA, A., El fundador del Opus Dei, cit., 80, 98. En diversas ocasiones, el fundador de la Obra recordó que había rechazado la posibilidad del sacerdocio antes de ese momento: «Yo nunca pensé en hacerme sacerdote, ni en dedicarme a Dios. No se me había presentado ese problema, porque creía que no era para mí. Más aún: me molestaba el pensamiento de poder llegar al sacerdocio algún día, de tal manera que me sentía anticlerical. Amaba mucho a los sacerdotes, porque la formación que recibí en mi casa era profundamente religiosa; me habían enseñado a respetar, a venerar el sacerdocio. Pero no para mí: para otros» (AGP, Biblioteca, P01, 1975, 218-219). 
antes, se había formado la comunidad de carmelitas varones de Logroño, compuesta solamente por tres personas: el hermano Pantaleón del Sagrado Corazón de Jesús, que había llegado a finales de noviembre de 1917; el padre Juan Vicente de Jesús María, que acudió a la ciudad el 11 de diciembre; y el padre José Miguel de la Virgen del Carmen, que se incorporó el 20 de diciembre ${ }^{16}$.

José María Escrivá comenzó a tener dirección espiritual con el padre José Miguel ${ }^{17}$. Incrementó la práctica cristiana que, en sus palabras, le condujo «a la comunión diaria, a la purificación, a la confesión... y a la penitencia» ${ }^{18}$. Al advertir las buenas disposiciones del joven, el padre José Miguel le animó dos o tres meses más tarde a que considerara la posibilidad de ser carmelita. Escrivá lo meditó con seriedad; incluso pensó que, en el caso de que fuera ése su camino, tendría como nombre de religión Amador de Jesús Sacramentado, por devoción a la Eucaristía. Pero muy pronto llegó a la conclusión de que Dios le llamaba a ser un presbítero secular ${ }^{19}$.

Ahora bien, esta determinación abarcaba algo más. José María pensó que su vocación no estaba orientada a ocupar un puesto en la estructura diocesana. Con sus palabras, «aquello no era lo que Dios me pedía, y yo me daba cuenta: no quería ser sacerdote para ser sacerdote, el cura que dicen en España. Yo tenía veneración al sacerdote, pero no quería para mí un sacerdocio así» ${ }^{20}$. En su interior sintió una llamada que era, a la vez, cierta e indeterminada, unos sentimientos que denominó después barruntos, es decir, presentimientos de que Dios le pedía algo más que, en cierto sentido, estaba unido al sacerdocio. Según afirmó, «yo no sabía lo que Dios quería de mí, pero era, evidentemente, una elección ${ }^{21}$. En este sentido, ser sacerdote se le presentaba como un elemento necesario y, a la

16 Toldrà PaRÉs, J., Josemaría Escrivá en Logroño, cit., 125.

17 Bernal, S., Mons. Fosemaría Escrivá de Balaguer. Apuntes sobre la vida del fundador del Opus Dei, Rialp: Madrid, 1980, 63-64.

${ }^{18}$ Nos parece relevante ofrecer la cita completa: «El Señor me fue preparando a pesar mío, con cosas aparentemente inocentes, de las que se valía para meter en mi alma esa inquietud divina... cosas que me removieron y me llevaron a la comunión diaria, a la purificación, a la confesión... y a la penitencia» (Meditación, 14-II-1964, en EsCrivá DE Balaguer, J., En diálogo con el Señor, edición crítico-histórica preparada por Luis Cano y Francesc Castells, cit., 200).

${ }^{19}$ Vázquez de Prada, A., El Fundador del Opus Dei, cit., 96, nt. 75.

${ }^{20}$ Meditación, 14-II-1964, en Escrivá DE BaLAgUeR, J., En diálogo con el Señor, edición críticohistórica preparada por Luis Cano y Francesc Castells, cit., 200. Sobre los diversos aspectos de su llamada al sacerdocio y los barruntos, ver ALONSO, J., «Vocación de san Josemaría», en ILLANES, J. L. (coord.), Diccionario de san Fosemaría Escrivá de Balaguer, cit., 1296-1300.

21 Apuntes de una meditación, 19-III-1975, en VÁZQueZ DE PRADA, A., El Fundador del Opus Dei, cit., 97. Escrivá tuvo claro que se trataba de una llamada o vocación divina; ver Apuntes intimos, n. 289 (17-IX-1931), en VázqueZ de Prada, A., El fundador del Opus Dei, cit., 100. 
vez, no suficiente para que los barruntos se aclarasen. Como dijo en una ocasión, «¿Por qué me hice sacerdote? Porque creí que era más fácil cumplir una voluntad de Dios, que no conocía» ${ }^{22}$; solamente el futuro le mostraría qué significaba, en su caso, que un presbítero es un pastor en la Iglesia.

Por entonces intensificó la plegaria de petición -«las luces no venían pero, evidentemente, rezar era el camino» ${ }^{23}$, apuntó-, pues estaba «persuadido de que Dios me quería para algo» ${ }^{24}$. Concretamente, recitaba dos breves frases en latín con las que rogaba conocer los designios de Dios. Decía: Domine, ut videam! (¡Señor, que vea!); Domine, ut sit! (¡Señor, que sea!).

Un buen día comunicó a su padre que quería entrar en el seminario. José Escrivá quiso cerciorarse y le preguntó: «¿Has pensado en el sacrificio que supone la vocación de sacerdote?». José María le respondió: «Solo he pensado, lo mismo que tú cuando te casaste, en el Amor» ${ }^{25}$. Al verle tan firme, su padre se conmovió hasta las lágrimas «porque tenía otros planes posibles, pero no se rebeló. Me dijo: -Hijo mío, piénsalo bien. Los sacerdotes tienen que ser santos... Es muy duro no tener casa, no tener hogar, no tener un amor en la tierra. Piénsalo un poco más, pero yo no me opondré» ${ }^{26}$. Solamente le sugirió que, además de la Teología, hiciera la carrera de Derecho -hasta ese momento, habían pensado que José María podía ser arquitecto, abogado o médico-, porque era compatible con los estudios eclesiásticos. Además, su padre le presentó a Antolín Oñate, un sacerdote conocido que era párroco y abad de la colegiata de La Redonda ${ }^{27}$.

En el verano de 1918, José María acabó el bachillerato con buenas calificaciones. Tras el periodo estivo, ingresó en el seminario de Logroño. Durante dos cursos académicos superó las asignaturas correspondientes del primer

22 AGP, P01, 1975, 218. En otra ocasión explicó que «esos barruntos de amor me llevaron al sacerdocio» (Homilía, 2-X-1968, cit. en AGP, Biblioteca, P06, vol. VI, 306).

23 Carta 25-V-1962, n. 41, en VÁzQueZ de PRADA, A., El Fundador del Opus Dei, cit., 175.

${ }^{24}$ Apuntes íntimos, n. 289 (17-IX-1931), en VÁZQUEZ DE PRADA, A., El fundador del Opus Dei, cit., 100. Las cursivas son del original.

25 Recuerdo de Luis Felipe Gómez Caballero, Gaztelueta (Bilbao), 9-VIII-1975, en AGP, serie A.5, 216-1-7.

${ }^{26}$ Meditación, 14-II-1964, en Escrivá De Balaguer, J., En diálogo con el Señor, edición críticohistórica preparada por Luis Cano y Francesc Castells, cit., 200. En otro momento, años más tarde, lo recordaba de modo semejante: «hablé con mi padre, diciéndole que quería ser sacerdote. Él no se esperaba esta salida. Fue la única vez -ya os lo he contado en otras ocasiones- que yo he visto lágrimas en sus ojos. Me respondió: mira, hijo mío, si no vas a ser un sacerdote santo, ¿por qué quieres serlo? Pero no me opondré a lo que deseas» (Apuntes de un encuentro familiar, 19-III-1975, en EsCRIVÁ DE BALAGUER, J., En diálogo con el Señor, edición crítico-histórica preparada por Luis Cano y Francesc Castells, cit., 403).

27 TOLDRÀ PARÉs, J., Fosemaría Escrivá en Logroño, cit., 130. 
año de Teología y participó en una catequesis los domingos por la mañana ${ }^{28}$. Ante sus compañeros era «responsable, buen estudiante, alegre, amable con todos, un tanto reservado y piadoso» ${ }^{29}$.

En la España de entonces, los hijos varones se encargaban de sacar adelante la propia familia. José María pensó que en su casa necesitaban otro varón y se lo pidió a Dios. En ese momento, José Escrivá tenía cincuenta y un años, y Dolores Albás cuarenta y uno. Hacía nueve años que no tenían hijos. Pero, con todo, el 28 de febrero de 1919 -diez meses después de que José María hubiese comentado la vocación sacerdotal con su padre-, nació Santiago Escrivá ${ }^{30}$. Este suceso impresionó a José María; entendió que también estaba en relación con los barruntos y con la llamada al sacerdocio: «Mi madre me llamó para comunicarme: vas a tener otro hermano. Con aquello toqué con las manos la gracia de Dios; vi una manifestación de Nuestro Señor. No lo esperaba» ${ }^{31}$.

Un año más tarde, en septiembre de 1920, José María Escrivá se trasladó a Zaragoza para continuar sus estudios eclesiásticos. La capital de Aragón rondaba los ciento cincuenta mil habitantes y tenía una creciente actividad agrícola e industrial. José María fue allí para seguir el consejo de su padre -la ciudad contaba con una facultad de Derecho- y también porque acabaría los estudios eclesiásticos en una universidad pontificia; viviría cerca de sus tíos Carlos Albás, que era canónigo de la catedral de Zaragoza, y de Mauricio Albás, que estaba casado; y, de ese modo, evitaría que le destinaran al pueblo de Calahorra para acabar la Teología, como era habitual entre los seminaristas riojanos.

Carlos Albás facilitó las gestiones para que su sobrino entrara en el seminario de San Francisco de Paula, donde le concedieron media beca. Desde el primer día de clase, José María acudió a la Universidad Pontificia de San Valero y San Braulio. En cambio, postergó el inicio de la carrera de Derecho hasta quinto de Teología para realizar bien ambos estudios. En el seminario recibió la formación tradicional propia del momento ${ }^{32}$.

28 TOLDRÀ PARÉs, J., Fosemaría Escrivá en Logroño, cit., 120-123.

29 Toldrà, J., «Seminario Conciliar de Logroño», en Illanes, J. L. (coord.), Diccionario de san Fosemaría Escrivá de Balaguer, cit., 1143.

30 Vázquez de Prada, A., El fundador del Opus Dei, cit., 109.

31 Meditación, 14-II-1964, en Escrivá De BaLaguer, J., En diálogo con el Señor, edición críticohistórica preparada por Luis Cano y Francesc Castells, cit., 199.

32 Los diversos pasos del joven Escrivá en el seminario de Zaragoza pueden verse en HERRANDo PRAT DE LA RIBA, R., Los años de seminario de fosemaría Escrivá en Zaragoza (1920-1925): El seminario de San Francisco de Paula, Madrid: Rialp, 2002; y HerRANDo PRAT DE LA RIBA, R., «Seminario de San Francisco de Paula», en Illanes, J. L. (coord.), Diccionario de san Fosemaría Escrivá de Balaguer, cit., 1146-1148. 


\section{LA ESENCIA DE LOS BARRUNTOS}

José María Escrivá estaba convencido de que Dios le inspiraba los barruntos de ese «algo» que vendría en el futuro. Por su misma naturaleza, los presentimientos eran claros en algunos aspectos e inciertos en otros. Como dijo después, «seguía viendo, pero sin precisar qué es lo que quería el Señor: veía que el Señor quería algo de mí. Yo pedía, y seguía pidiendo» ${ }^{33}$. Siempre que podía, acudía a la capilla de la Virgen del Pilar para solicitar el conocimiento de la voluntad divina. Empleaba una jaculatoria semejante a otras que utilizaba: Domina, ut sit! (¡Señora, que sea!); y reforzaba su súplica con frases del evangelio que a veces decía en voz alta o incluso cantaba: «Ignem veni mittere in terram et quid volo nisi ut accendatur?; he venido a poner fuego a la tierra, ¿y qué quiero sino que arda? Y la contestación: Ecce ego quia vocasti me!, aquí estoy, porque me has llamado» ${ }^{34}$.

Coincidiendo con la llegada a la capital aragonesa, se sintió «impulsado a escribir, sin orden ni concierto» ${ }^{35}$, en $\ll$ notas sueltas ${ }^{36}$, sin ilación clara, diversas mociones y sucesos de su vida interior. A algunas de estas inspiraciones, en las que sentía la providencia de Dios, las denominaba «operativas, porque de tal manera dominaban mi voluntad que casi no tenía que hacer esfuerzo» ${ }^{37}$. Eran ideas confusas; a veces incluso apuntaban hacia una fundación, pero sin nada concreto.

En cambio, el fundamento de esos barruntos se le hacía patente. Radicaba en una relación íntima con Dios, en «algo tan hermoso como enamorarse» ${ }^{38}$. Años más tarde, condensaría esta etapa de su vida con las siguientes palabras: «comencé a barruntar el Amor, a darme cuenta de que el corazón me pedía algo grande y que fuese amor» ${ }^{39}$. Y, como fruto de ese arrebato interior,

33 Apuntes íntimos, n. 179, en VÁZqueZ de PradA, A., El fundador del Opus Dei, cit., 117. Estas palabras del fundador fueron transcritas por Álvaro del Portillo en 1968.

${ }^{34}$ Meditación, 2-II-1962, en Escrivá de Balaguer, J., En diálogo con el Señor, edición críticohistórica preparada por Luis Cano y Francesc Castells, cit., 179.

35 Apuntes íntimos, n. 414 (24-XI-1931), en VÁZQUEZ DE PRADA, A., El fundador del Opus Dei, cit., 247.

36 Apuntes íntimos, n. 306 (2-X-1931), en VÁZqueZ de PradA, A., El fundador del Opus Dei, cit., 293.

37 Meditación, 14-II-1964, en Escrivá De Balaguer, J., En diálogo con el Señor, edición críticohistórica preparada por Luis Cano y Francesc Castells, cit., 201.

38 Apuntes de un encuentro familiar, en AGP, Biblioteca, P01, 1968, 450.

39 Apuntes de un encuentro familiar, 19-III-1975, en Escrivá DE BALAGUER, J., En diálogo con el Senor, edición crítico-histórica preparada por Luis Cano y Francesc Castells, cit., 403. Al final de su vida, repitió varias veces esta idea: «Yo barruntaba el amor de Dios, pero no sabía que era tan inmenso» (Apuntes de un encuentro familiar, 11-VII-1974, en AGP, Biblioteca, P06, vol. V, 117). 
se le acrecentaba el deseo de rezar y de cumplir la voluntad de Dios, como escribió: «verdaderamente, el Señor dilató mi corazón, haciéndolo capaz de amar, de arrepentirse, de servir, aun a pesar de mis errores» ${ }^{40}$.

Las limitaciones en la educación humana de algunos seminaristas de $\mathrm{Za}-$ ragoza y las incomprensiones con el rector del seminario pusieron en crisis su vocación sacerdotal. En el verano de 1921 José María buscó la dirección espiritual de un sacerdote en Logroño que, al advertir que tenía las disposiciones adecuadas, le animó a seguir adelante. El joven se decidió y, un año más tarde, en septiembre de 1922, recibió la tonsura -que le incorporaba oficialmente al estado clerical- y fue nombrado inspector del seminario por el arzobispo de Zaragoza, el cardenal Juan Soldevila ${ }^{41}$.

En 1923 comenzó la carrera de Derecho, como alumno libre, en la Universidad de Zaragoza. Se trataba de una facultad pequeña -trescientos treinta y un alumnos, de los cuales doscientos cuarenta y dos libres-, con profesores de prestigio nacional. Salvo dos exámenes del preparatorio, José María no acudió a las clases de la facultad de Derecho ni se examinó hasta que no acabó los estudios de la licenciatura de Teología, en junio de 1924.

Este ritmo lento en el estudio del Derecho y su deseo de no «hacer carrera» eclesiástica disgustaban a su tío Carlos, que quería que José María opositara lo antes posible. El joven, en cambio, «consideraba que los estudios universitarios le permitirían estar más disponible para el cumplimiento de la voluntad divina» ${ }^{42}$. En este sentido, tal vez pensó que la carrera de Derecho también formaba parte del ámbito en el que se movían los barruntos (más adelante, la formación jurídica recibida le ayudaría a buscar caminos a través de los cuales situaría al Opus Dei dentro del ordenamiento canónico de la Iglesia).

El 14 de junio de 1924 recibió el subdiaconado. Cinco meses más tarde, el 27 de noviembre, su padre falleció repentinamente en Logroño y José María quedó como cabeza de familia. Entonces decidió que los suyos se trasladasen a Zaragoza. Esta mudanza motivó un fuerte choque con su tío. Si, años antes, Carlos Albás no había entendido las resoluciones que adoptó José Escrivá cuando quebró su empresa, ahora no deseaba que su hermana e hijos fuesen a residir a Zaragoza porque se encontraban en franca penuria. Pensaba que era

${ }^{40}$ Carta 25-I-1961, n. 3, en AGP, Biblioteca, P06, vol. VI, 397.

${ }^{41}$ HerRando Prat de la Riba, R., Los años de seminario de fosemaría Escrivá en Zaragoza (19201925), cit., 160-162.

42 Baltar RodrígueZ, J. F., «Los estudios de Derecho de san Josemaría en la Universidad de Zaragoza», Studia et Documenta 9 (2015) 231. 
más oportuno que José María se ordenase presbítero y que se situara en la diócesis; después, podría reencontrarse con la familia. Pero, como el sobrino no siguió su consejo, se produjo la ruptura.

El 20 de diciembre de 1924, Miguel de los Santos Díaz Gómara, obispo auxiliar de Zaragoza, confirió el diaconado a José María; y el 28 de marzo de 1925 le ordenó sacerdote. A los dos días, José María celebró la Primera Misa en la santa capilla del Pilar en sufragio por su padre. Asistieron su madre y hermanos, unos primos, la familia de un profesor amigo y unos pocos invitados más; en cambio, no estuvieron presentes ninguno de sus tres tíos sacerdotes. $\mathrm{Al}$ acabar la Misa, el joven presbítero se retiró a la sacristía. Y, después de desvestirse, lloró a Dios con desconsuelo ${ }^{43}$.

Luego pasó un mes y medio en un pequeño pueblo de la provincia llamado Perdiguera. Tuvo así la primera experiencia pastoral en la administración de los sacramentos y en la atención de los fieles mediante la dirección espiritual ${ }^{44}$. Cuando regresó a Zaragoza, la curia diocesana no le otorgó un nombramiento para trabajar en la pastoral ordinaria como, por ejemplo, colaborar en una parroquia. José María Escrivá consiguió un puesto como capellán de la iglesia de San Pedro Nolasco, que estaba regentada por los jesuitas. Este cargo le exigía celebrar la Misa y dedicar un tiempo al confesionario. El resto del día lo dedicaba a asistir a clase y a estudiar las asignaturas de Derecho ${ }^{45}$.

La relación con el mundo académico le resultó enriquecedora. Escrivá mostraba una mentalidad laical poco común entre el clero. Por ejemplo, en los intervalos entre una lección y otra no se reunía sólo con sacerdotes o seminaristas, sino que buscaba el diálogo con los estudiantes laicos; no pedía privilegios a la hora de hacer los exámenes o de asistir a clase; y tampoco «sermoneaba» cuando hablaba con los demás. Por eso, algunos compañeros le cobraron particular aprecio y le confiaban asuntos personales o le acompañaban por la calle.

En su actividad ministerial, tuvo relación con universitarios de las Congregaciones Marianas, dirigidas por los jesuitas. Además, acompañado por unos cuántos jóvenes, los domingos enseñó la doctrina cristiana a niños de familias de

43 Vázquez de Prada, A., El fundador del Opus Dei, cit., 194-197; y GonZález Gullón, J. L., «Anotaciones de Ricardo Fernández Vallespín en la Academia DYA de Madrid (18 de marzo-25 de junio de 1934)», Studia et Documenta 7 (2013) 401.

${ }^{44}$ Ferrer Ortiz, J., «Perdiguera», en Illanes, J. L. (coord.), Diccionario de san fosemaría Escrivá de Balaguer, cit., 966-967.

45 RodrígueZ, P., «El doctorado de san Josemaría en la Universidad de Madrid», Studia et Documenta 2 (2008) 45, nt. 114. 
escasos recursos del barrio de Casablanca, a la salida de Zaragoza. El contacto con los necesitados incrementó su deseo de servir a los demás con el sacerdocio.

Desde hacía tiempo -de modo particular desde la muerte de su padre-, tenía la idea de hacer el doctorado en Derecho y de ocupar una cátedra universitaria. Quería llevar la doctrina cristiana al mundo académico pues, cuando contemplaba a sus compañeros de Facultad, los veía «un poco como "ovejas sin pastor" $\gg^{46}$. Ahora bien, como le aconsejó un sacerdote amigo, el catedrático José Pou de Foxá, debería abrirse camino fuera de Zaragoza, ya que allí «no tenía campo ${ }^{47}$ dadas las dificultades con su tío.

\section{LA PLENITUD DE LA LLAMADA}

Hacia septiembre de 1926, José María viajó a Madrid para informarse sobre cómo podía realizar el doctorado. Cuando regresó a Zaragoza, y como forma de ganar algo de dinero para su familia, dio clase de repaso de Derecho Romano, Canónico, Historia del Derecho y Derecho Natural en el Instituto Amado.

En enero de 1927 se licenció en Derecho. Dos meses más tarde, solicitó el traslado del expediente académico a Madrid para hacer el doctorado en la Universidad Central. Y, al poco -después de una breve sustitución de un sacerdote en un pueblo de Zaragoza, Fombuena- dejó la capital aragonesa.

José María Escrivá llegó a Madrid el 20 de abril ${ }^{48}$. Se matriculó en los cursos de doctorado de la Facultad de Derecho y se alojó en la Casa Sacerdotal para presbíteros extradiocesanos. Esta residencia estaba regentada por las damas apostólicas del Sagrado Corazón de Jesús, una nueva congregación religiosa. Un mes más tarde, la fundadora de las damas apostólicas le ofreció ser capellán de la iglesia del Patronato de Enfermos, sede central de las religiosas y centro de diversas actividades benéficas ${ }^{49}$.

El 1 de junio, don José María comenzó en el Patronato de Enfermos su trabajo pastoral, que consistía en la celebración de la Misa, la exposición de

\footnotetext{
${ }^{46}$ Recuerdo de Arsenio Górriz Monzón, Teruel, XII-1975, en AGP, serie A.5, 218-1-8.

47 Recuerdo de F. Javier de Ayala (que cita una conversación con Pou de Foxá), São Paulo, 8-IX1979, en AGP, serie A.5, 196-2-7.

${ }^{48}$ Puede verse un breve análisis de la capital española en ese momento en MonTERo, J. y CerveRA GIL, J., «Madrid en los años treinta. Ambiente social, político, cultural y religioso», Studia et Documenta 3 (2009) 4513-4539.

49 Vázquez de Prada, A., El fundador del Opus Dei, cit., 257.
} 
la Eucaristía, la atención del confesonario y, por la tarde, el rezo del rosario y la bendición con el Santísimo Sacramento. Además, los fines de semana estaba disponible para confesar a los niños de las escuelas semi-gratuitas promovidas por las damas apostólicas. Y, aunque no formase parte de sus obligaciones como capellán, muchas tardes visitaba a enfermos de escasos recursos en sus domicilios para llevarles la Comunión o impartirles la reconciliación sacramental ${ }^{50}$.

Cinco meses después, José María alquiló un apartamento para que su madre y sus hermanos viviesen con él. En ese curso académico, consiguió un puesto como profesor de Derecho Romano y de Canónico en la «Academia Cicuéndez», un centro privado de enseñanza que preparaba el ingreso en la Facultad de Derecho y reforzaba la explicación de algunas asignaturas. El sacerdote impartió clase en esta Academia dos tardes a la semana, durante más de cuatro años, para ayudar económicamente a la familia ${ }^{51}$.

El 30 de septiembre de 1928, José María Escrivá acudió al convento de los paúles -situado en el norte de Madrid- para hacer los ejercicios espirituales. Seis sacerdotes se habían apuntado a aquella tanda. El martes 2 de octubre, después de celebrar la Misa, se retiró a su habitación para leer unos papeles en los que había anotado con anterioridad ideas y sucesos que consideraba inspirados por Dios y que formaban parte de los barruntos. De repente, «se dio cuenta de la hermosa y pesada carga que el Señor, en su bondad

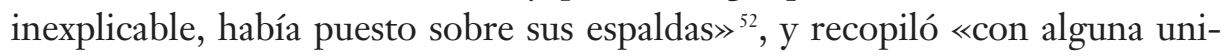
dad las notas sueltas, que hasta entonces venía tomando ${ }^{53}$. En ese momento, de gran intensidad, «acabó de ver claramente la Voluntad de Dios» ${ }^{54}$ por la que llevaba tantos años rezando. ¿Qué había ocurrido?

El joven sacerdote recibió una luz de carácter sobrenatural que le situaba en el corazón del misterio cristiano. Tuvo una «iluminación sobre toda la Obra $\gg^{55}$,

${ }^{50}$ Las visitas de Escrivá a domicilios de personas necesitadas han sido estudiadas por GONZÁLEZSimancas y LaCASA, J., «San Josemaría entre los enfermos de Madrid (1927-1931)», Studia et Documenta 2 (2008) 147-203.

51 Ver ÁnCHEL, C., «Actividad docente de san Josemaría: el Instituto Amado y la Academia Cicuéndez», Studia et Documenta 3 (2009) 330.

52 Apuntes intimos, n. 306 (2-X-1931), en VÁZqueZ DE PRADA, A., El fundador del Opus Dei, cit., 302. Las cursivas de los textos citados son del original.

53 Apuntes íntimos, n. 306 (2-X-1931), en VÁZQUEZ DE PRADA, A., El fundador del Opus Dei, cit., 293.

54 Apuntes intimos, n. $978 \mathrm{~b}(10-\mathrm{IV}-1933)$.

55 Apuntes íntimos, n. 306, en Vázquez DE Prada, A., El fundador del Opus Dei, cit., 293. Esta frase es una nota marginal de Escrivá de 1968. 
una «idea clara general de mi misión» ${ }^{56}$ que abría un «panorama apostólico inmenso» ${ }^{57}$. Conmovido porque «quiso Jesús que se comenzara a dar forma concreta a su Obra $\gg^{58}$, se arrodilló y dio gracias a Dios. Acababa de nacer el Opus Dei. Entonces, escuchó el sonido de las campanas de la parroquia de Nuestra Señora de los Ángeles, que llamaban a los fieles a Misa; más adelante, consideró este hecho como una muestra de la intercesión de Santa María y de los ángeles en el momento fundacional ${ }^{59}$.

De este modo, la llamada divina que José María Escrivá había sentido en Logroño a finales de 1917 o principios de 1918 eclosionaba en aquel octubre de 1928. Para el entonces joven sacerdote, todos los hechos pasados de su vida -y también los que vendrían en el futuro- adquirían pleno sentido vocacional. Escrivá estaba emplazado a encarnar y difundir el mensaje de santidad cristiana en medio del mundo, y a fundar, con ese fin, una institución que viviera y plasmara ese ideal. Como apuntó después, Dios le convocaba a ser «santo y padre, maestro y guía de santos» ${ }^{60}$.

${ }^{56}$ Apuntes íntimos, n. 179, en VÁZquez de Prada, A., El fundador del Opus Dei, cit., 298, nt. 118. Estas palabras del fundador fueron transcritas por Álvaro del Portillo en 1968.

57 Carta de Josemaría Escrivá a José María Hernández Garnica, Roma, 29-I-1948, en AGP, serie A.3.4, 260-1, 480129-2.

58 Apuntes íntimos, n. 331 (15-X-1931). La expresión «Obra de Dios» referida a la institución, al Opus Dei, es de 1930. Entre 1928 y 1930 Escrivá no tenía todavía un nombre para definirla.

59 Para un estudio sobre lo ocurrido y el sentido del 2 de octubre de 1928, que desborda el análisis de estas páginas, remitimos a ARANDA, A., «El bullir de la Sangre de Cristo». Estudio sobre el cristocentrismo del beato Fosemaría Escrivá, Madrid: Rialp, 2000; ETEROVIC GARNET, D., «La luz del 2 de octubre de 1928: un estudio de fuentes», en Un mensaje siempre actual. Actas del Congreso «Hacia el centenario del nacimiento del beato fosemaría Escrivá de Balaguer», Buenos Aires: Universidad Austral, 2002, 521-539; ILlANES MAESTRE, J. L., «Datos para la comprensión histórico-espiritual de una fecha», Anuario de Historia de la Iglesia XI (2002) 655-697; REDONDO, G., «El 2 de octubre de 1928 en el contexto de la historia cultural contemporánea», Anuario de Historia de la Iglesia XI (2002) 699-741; RodríGUEZ, P., Opus Dei: Estructura y Misión. Su realidad eclesiológica, Madrid: Cristiandad, 2001; y VÁZQUEZ DE PRADA, A., El fundador del Opus Dei, cit., 251-495.

60 Apuntes intimos, n. 1725 (22-VI-1933), en VÁZQUEZ DE PraDA, A., El fundador del Opus Dei, cit., 554. 


\section{Bibliografía}

Alonso, J., «Vocación de san Josemaría», en Illanes, J. L. (coord.), Diccionario de san Fosemaría Escrivá de Balaguer, Burgos: Monte Carmelo e Instituto Histórico San Josemaría Escrivá, 2013, 1296-1300.

ÁnCHEL, C., «Actividad docente de san Josemaría: el Instituto Amado y la Academia Cicuéndez», Studia et Documenta 3 (2009) 307-333.

ARANDA, A., «El bullir de la Sangre de Cristo». Estudio sobre el cristocentrismo del beato Fosemaría Escrivá, Madrid: Rialp, 2000.

Baltar Rodríguez, J. F., «Los estudios de Derecho de san Josemaría en la Universidad de Zaragoza», Studia et Documenta 9 (2015) 231.

Bernal, S., Mons. Fosemaría Escrivá de Balaguer. Apuntes sobre la vida del fundador del Opus Dei, Madrid: Rialp, 1980.

Escrivá de Balaguer, J., Camino. Edición crítico-bistórica preparada por Pedro Rodríguez, $3^{\text {a }}$ ed., Madrid: Rialp, 2004.

EsCRIVÁ DE BALAGUER, J., En diálogo con el Señor, edición crítico-histórica preparada por Luis Cano y Francesc Castells, Madrid: Rialp, 2017.

ETEROVIC GARNET, D., «La luz del 2 de octubre de 1928: un estudio de fuentes», en Un mensaje siempre actual. Actas del Congreso «Hacia el centenario del nacimiento del beato fosemaría Escrivá de Balaguer», Buenos Aires: Universidad Austral, 2002, 521-539.

Ferrer Ortiz, J., «Perdiguera», en Illanes, J. L. (coord.), Diccionario de san Fosemaría Escrivá de Balaguer, Burgos: Monte Carmelo e Instituto Histórico San Josemaría Escrivá, 2013, 966-967.

GarRIDO, M., Barbastro y el Beato Fosemaría Escrivá, Barbastro: Ayuntamiento de Barbastro, 1995.

GonZÁlez Gullón, J. L., «Anotaciones de Ricardo Fernández Vallespín en la Academia DYA de Madrid (18 de marzo-25 de junio de 1934)», Studia et Documenta 7 (2013) 371-402.

GonZÁlez Gullón, J. L., DYA. La Academia y Residencia en la historia del Opus Dei (1933-1939), Madrid: Rialp, 2016.

GONZÁlEZ-Simancas y LaCASA, J., «San Josemaría entre los enfermos de Madrid (1927-1931)», Studia et Documenta 2 (2008) 147-203.

HerRando PRAT DE la Riba, R., Los años de seminario de fosemaría Escrivá en Zaragoza (1920-1925): El seminario de San Francisco de Paula, Madrid: Rialp, 2002.

Herrando Prat de la Riba, R., «Seminario de San Francisco de Paula», en Illanes, J. L. (coord.), Diccionario de san fosemaría Escrivá de Balaguer, Bur- 
gos: Monte Carmelo e Instituto Histórico San Josemaría Escrivá, 2013, $1146-1148$.

IbarRa Benlloch, M., «Josemaría Escrivá de Balaguer y el colegio de las Escuelas Pías de Barbastro (1908-1915)», Studia et Documenta 7 (2013) 201-220.

ILLANES MAESTRE, J. L., «Datos para la comprensión histórico-espiritual de una fecha», Anuario de Historia de la Iglesia XI (2002) 655-697.

Montero, J. y Cervera Gil, J., «Madrid en los años treinta. Ambiente social, político, cultural y religioso», Studia et Documenta 3 (2009) 4513-4539.

Mora-Figueroa, J., «Barbastro», en Illanes, J. L. (coord.), Diccionario de san Fosemaría Escrivá de Balaguer, Burgos: Monte Carmelo e Instituto Histórico San Josemaría Escrivá, 2013, 153-157.

OCÁRIZ, F., «La vocación al Opus Dei como vocación en la Iglesia», en RoDRÍGUEZ P., OCÁRIZ, F. e Illanes, J. L., El Opus Dei en la Iglesia, 6a ed., Madrid: Rialp, 2014, 133-193.

Pioppi, C., «Infanzia e prima adolescenza di Josemaría Escrivá: Barbastro 1902-1915. Contesti, eventi biografici, stato delle ricerche e prospettive di approfondimento», Studia et Documenta 8 (2014) 149-189.

RedOnDO, G., «El 2 de octubre de 1928 en el contexto de la historia cultural contemporánea», Anuario de Historia de la Iglesia XI (2002) 699-741.

RodrígueZ, P., «Apuntes íntimos (obra inédita)», en IllaNES, J. L. (coord.), Diccionario de san Fosemaría Escrivá de Balaguer, Burgos: Monte Carmelo e Instituto Histórico San Josemaría Escrivá, 2013, 131-135.

RodrígueZ, P., «El doctorado de san Josemaría en la Universidad de Madrid», Studia et Documenta 2 (2008) 13-103.

RodrígueZ, P., Opus Dei: Estructura y Misión. Su realidad eclesiológica, Madrid: Cristiandad, 2001.

TOldRÀ, J., «Instituto General y Técnico de Logroño», en Illanes, J. L. (coord.), Diccionario de san Fosemaría Escrivá de Balaguer, Burgos: Monte Carmelo e Instituto Histórico San Josemaría Escrivá, 2013, 643-644.

TOldRÀ, J., «Seminario Conciliar de Logroño», en Illanes, J. L. (coord.), Diccionario de san Fosemaría Escrivá de Balaguer, Burgos: Monte Carmelo e Instituto Histórico San Josemaría Escrivá, 2013, 1142-1143.

TOldrà ParÉs, J., fosemaría Escrivá en Logroño (1915-1925), Madrid: Rialp, 2007. Toranzo, E., Toranzo, G. y Toranzo, E. L., Una familia del Somontano, Madrid: Rialp, 2004.

VÁZqueZ de Prada, A., El Fundador del Opus Dei, vol. I («iSeñor, que vea!»), Rialp, Madrid 1997. 

A los cincuenta años de
Humanae vitae 
